\title{
Innovated water-reuse through redistribution schema, benefits and challenges
}

\author{
Kostandin Kristo \\ PhD Student, Applied Statistics and Informatics Department \\ University of Tirana, Albania
}

\begin{abstract}
The drought regarding a climate forecast Albanian departments have marked the past three months were the result of winter rainfall that was insufficient for replenishing water tables this year and before. We often say that water shortages are not a threat for our country due to plenty water sources . It's possible to think this when we compare our situation to that in other countries. Still , in some regions the availability of water resources is becoming an urgent problem, even more so if we link this to the different scenarios tied to climate change. Each basin has specificities, but some general evolutions should be planned for ,increase in water demand due to the rise in temperatures, causing an increase in the price of water and usage conflicts, change in the amount of the available water resources, changes in the flow of waterways and the aquifer recharge ,decrease in water quality ( meaning a concentration of pollutants and a weakening in self-purification capacities) rise in nitrates in waterways and in aquifers may occur, as well as increased salinity levels, increase in the vulnerability of certain ecosystems due to the rise in the risk of erosion, flooding and salting. This paper aims to introduce the benefits and challenges of applying at homes or communal buildings of an Eco-innovation , through developing a new inside distribution of wastewater so that it concludes into sustainable development of inside communal water distribution, therefore recycling inside the house. The main objective of the study is to make evident the costefficiency importance of these re-distribution systems, and how they affect improvement in water needs sector , highlighting the deficiencies that cause their not fully-efficient re-use of grey inside water and the positive impact on the potable water saving .
\end{abstract}

Keywords: reclaimed water, sustainable development, eco-innovation, technological change .

JEL Classification: 030, 031,032,033.

\section{Introduction}

\subsection{Eco-innovation Concept}

The idea of eco-innovation [1] is fairly recent. One of the first appearances of the concept of eco-innovation in the literature is in the book by Claude Fussler and Peter James. In a subsequent article, Peter James defines eco-innovation as "new products and processes which provide customer and business value but significantly decrease environmental impacts". Klaus Rennings introduces the term eco-innovation addressing explicitly three kinds of changes towards sustainable development: technological, social and institutional innovation.

As a technological term

Many industries have been developing innovative technologies in order to work towards sustainability .

As a social process

Eco-innovations should also bring greater social and cultural acceptance. In this view, this "social pillar" added to James's ${ }^{[2]}$ definition is necessary because it determines learning and the effectiveness of eco-innovations.

Diffusion 
Literature in the field of eco-innovations often focuses on policy, regulations, technology, market and firm specific factors rather than diffusion. However, understanding of diffusion of eco-innovation recently has gained more importance given the fact that some eco-innovations are already at a mature stage. ${ }^{[3]}$

\section{Outline of the EU water framework Directive .}

The increasing demand by citizens and environmental organizations for cleaner rivers and lakes, groundwater and coastal beaches has been evident for considerable time.

Whilst EU actions of the past such as the Drinking Water Directive and the Urban Waste Water Directive can duly be considered milestones, European Water Policy ${ }^{[4]}$ has to address the increasing awareness of citizens and other involved parties for their water. At the same time water policy and water management are to address problems in a coherent way. This is why the new European Water Policy was developed in an open consultation process involving all interested parties.

\subsection{International Water Association water politics .}

The IWA Principles ${ }^{[5]}$ for Water-Wise Cities assist leaders to develop and implement their vision for sustainable urban water, beyond equitable universal access to safe drinking water and sanitation. The ultimate goal of these Principles is to encourage collaborative action, underpinned by a shared vision, so that local governments, urban professionals, and individuals actively engage in addressing and finding solutions for managing all waters of the city ${ }^{[5]}$.

With increasing numbers of people living in metropolitan areas, water, energy and materials need to be used carefully, reused and renewed.

Water is essential for the well-being of citizens, their safety and social inclusion in cities.

Planning systems with increased modularity and reduced dependencies enable a better reactivity to unforeseen trends and events.

Governance and institutions provide the framework for urban stakeholders to work together, breaking silos to integrate water in all urban services at the building, neighborhood, metropolitan and catchment scales.

Implementing the sustainable urban water vision starts with the existing capacities and competencies of the different urban stakeholders.

Asset management, master plans or decision support systems are the means for urban stakeholders to initiate action.

Based on quality assurance, equity, transparency, accountability and sound financing, they provide a solid frame for stakeholders to invest in sustainable urban water. Financial tools, linked to rigorous asset management plans, enable long lasting improved service levels with a well maintained infrastructure.

Regenerative water services are underpinned by five principles. Embedding these principles in water and wastewater systems rehabilitation, extension or new development will ensure the resource is protected and not overused. It will create value from energy and resource recovery not only from water but also from other services, and will facilitate financing by generating new revenue whilst delivering broader economic, social and environmental benefits to the city:

Replenish water bodies and their ecosystems within the basin by taking from or discharging to them only what can be given or absorbed by the natural environment. Reduce water protect the quality of water sources from wastewater and urban run-off so that it is fit for ecosystems and for use with minimal treatment requirements.

Reduce the amount of water and energy used. Minimize the amount of water used in accordance with storage capacities.

Reuse and use diverse sources of water with treatment that matches the use, applying the "fit for purpose" water quality approach and Integrated Water Resources Management (IWRM5)

Recover energy from water whether through heat, organic energy or hydraulic energy and recognize the value of "upcycled" materials, such as nutrients or organic matter;

Use a SYSTEMIC APPROACH ${ }^{[6]}$ integrated with other urban services. 
INCREASE THE MODULARITY [7]and ensure there are multiple resource, treatment, storage and conveyance options available throughout the system for ensuring service levels and resilience of urban water systems in the face of either gradual or sudden changes.

WATER SENSITIVE URBAN DESIGN seeks the integration of urban planning with the management, protection and conservation of the total urban water cycle to produce urban environments that are 'sensitive' to water sustainability .

Design domestic and industrial precincts and buildings in ways that enables regenerative water services.

WATER-WISE COMMUNITIES [7]The implementation of the previous three sets of Principles requires a holistic approach and strong partnerships.

Citizens involved in the sustainable urban water vision.

PROFESSIONALS WITH VARIOUS EXPERTISE (FINANCE, TECHNICAL, SOCIAL) [8]who understand the co-benefits across urban sectors so that they may plan and implement the best solutions for urban dwellers and businesses.

\section{Introduction of my waste-water reuse Idea .}

Water underpins every aspect of human and environmental existence. The severe water challenges facing the world today require an unprecedented global response. Innovative, solutions- and service- oriented, so many entities work across a range of areas that contribute to the progression of water management worldwide.

Most of their programs develop research and projects focused on solutions for water and wastewater management ; organizes world-class events that bring the latest science, technology and best practice to the water sector at large; works to place water on the global political agenda and to influence best practice in regulation and policy making .

Water/wastewater reuse, as an alternative water source, can provide significant economic, social and environmental benefits, which are key motivators for implementing such reuse programs. Specifically, in agriculture, irrigation with wastewater may contribute to improve production yields, reduce the ecological footprint and promote socioeconomic benefits

Eco-innovation is the development of products and processes that contribute to sustainable development ${ }^{[2]}$, applying the commercial application of knowledge to elicit direct or indirect ecological improvements. My case includes an environmentally idea consisting at technological acceptable innovative paths towards sustainable redirection of communal wastewater .

\section{Standard Water}

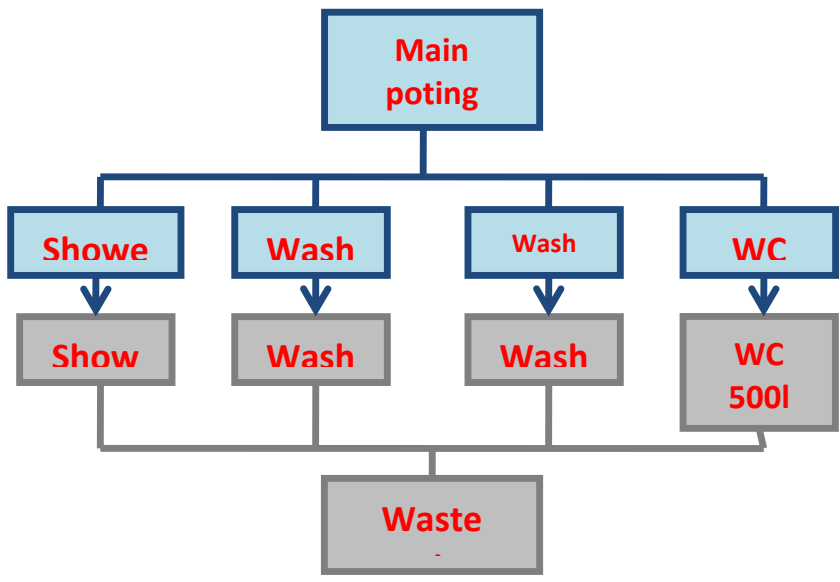




\section{Redistribution of inside waters}

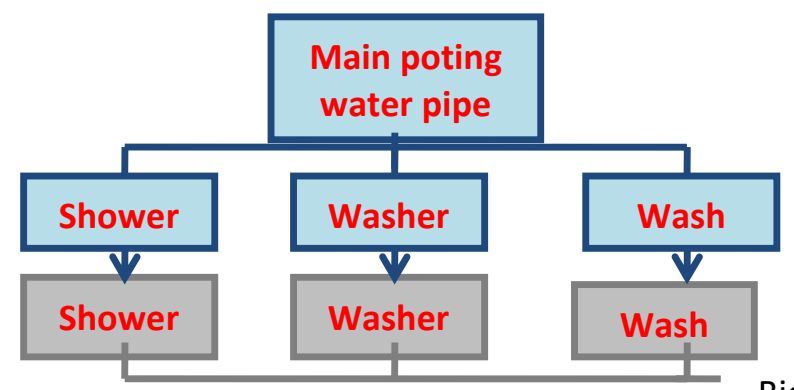

Biomecha

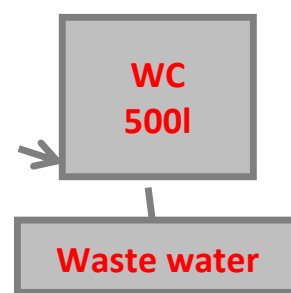

My proposed redistribution scheme of water:

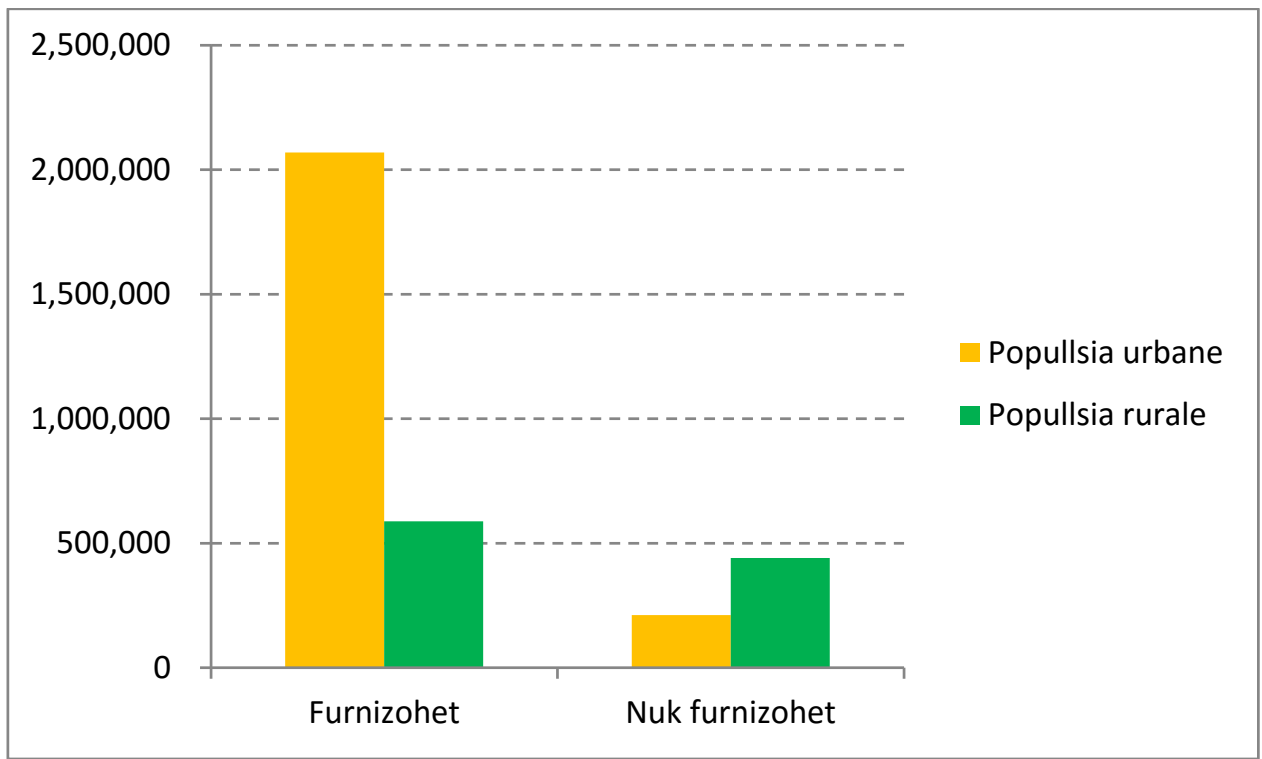

Drinking Water Indicators (Albania) ${ }^{[9]}$

\begin{tabular}{|l|l|l|}
\hline $\begin{array}{l}\text { Population living in the area of } \\
\text { jurisdiction of all societies }\end{array}$ & $3,307,937$ & $3,307,937$ \\
\hline $\begin{array}{l}\text { The population actually supplied with } \\
\text { water by societies }\end{array}$ & $80.3 \%$ & $2,656,267$ \\
\hline
\end{tabular}




\begin{tabular}{|l|l|l}
\hline Population that is not supplied & $19.7 \%$ & 651,670
\end{tabular}

Source: MPWTT, Processing and comments: ODA

\subsection{A benefits of my WATER INSIDE REUSE SYSTEM .}

This paper is offered as practical/experiential paper based on my individual experience at home during one month trying to measure how many times each person at my family daily uses the potable water discharging into the toilet . I thought , nature is working so long to prepare potable water and in 1 second without thinking twice about it , we let this glorious and unsavory action of nature became exhaustive scarcity .

Wade Miller, executive director of the Water Reuse Association California estimates that seven out of every 100 gallons [6] of U.S. wastewater gets recycled near its source, and said that number is growing about 5 percent annually, but the this is not potable water.

Comparing with above estimation, as you can see at the schema above ( my proposed Idea) the percentage of return is $50 \%$ potable water, simply due to spare redirection inside wastewater .

In Albania as you can see at the table above , to 19.7 percent of population is not supplied

potable water by societies .

Let us call it the kick-start of more wastewater inside reuse in Elbasan city , I would say .

Water reuse can reduce the amount of freshwater diverted from sensitive ecosystems, as well as the amount of wastewater - and the pollution it carries - discharged to waterways. In the case of non potable reuse, it means avoiding the use of precious potable water where that level of quality is not required.

And, while wastewater reuse is energy intensive, it often yields an energy savings because pumping imported water (from outside sources) consumes so much energy itself.

While we'll always need that supply, it does take a lot of energy to do that. Reusing water inside takes less.

\subsection{Challenges and hurdles}

Water reuse, however principally, is not automatically right for every circumstance. There are a lot of places where the wastewater would have otherwise been important in returning to. By recycling waste water we're interrupting a while return of the water to the natural environment.

Water reuse is also expensive. Potable reuse systems require a high degree of treatment, and non potable systems require a separate piping system to distribute the water, which can add up to as much as, or more than, potable treatment. The really low-cost sources of water have pretty much already been developed. So this source of water's not inexpensive. New sources of water are even more expensive, by and large.

There are also challenges, particularly with non potable reuses such as irrigation, in dealing with seasonal fluctuations in demand.

The biggest hurdle, however, lies in gaining public acceptance. When people hear about "toilet to tap" technology, they get nervous - and grossed out [5]. That's why when municipalities look at reuse, the hardest part usually isn't figuring out the right technology or engineering the system; it's educating the public and involving them in the process in order to gain their approval.

\section{Some eco-innovation experiences to be compared with my idea .}

\subsection{California case ; Wastewater reuse innovation}

The more notable change, however, is that a growing number of municipalities are shifting toward or considering "potable reuse" - recycling wastewater into drinking water. 
In 2008, Orange County started operating its now-celebrated Groundwater Replenishment System [3], which injects treated wastewater into the water supply of nearly 600,000 residents. The project, is taking water reuse to the next level. Instead of pouring it on the ground, in terms of landscape irrigation, they were turning it into drinking water."

It's on track to reach 100 million gallons per day by 2015. The system has attracted interest both nationally and internationally. They have recently hosted officials from Japan and the United Arab Emirates, and his team also has been working with England and even Singapore, which already has a potable reuse system supplying about 30 percent of its drinking water. (Reuse is also already established and growing in Australia and some European countries.)

The Orange County system, like most potable reuse projects today, practices "indirect" reuse, which means there's an environmental buffer - a groundwater basin, say, or a reservoir - between the wastewater process and the municipal water supply intake. In direct potable reuse, there's no environmental buffer; water is treated and sent directly back to the municipal water supply. It's something that more, primarily arid, places are starting to consider as a way to make the most of their increasingly scarce water resources.

Experts say reuse technologies have been proven, and treatment plants can get wastewater as clean as distilled water. The three-step process used in Orange County ${ }^{[3]}$ - microfiltration, reverse osmosis and a combination of ultraviolet treatment with hydrogen peroxide - is becoming the standard for potable reuse. Direct potable reuse is already practiced, largely as an answer to increasing drought, in Big Spring, Texas, and in the southern African nation of Namibia, which boasts the world's first major direct potable reuse system. Cloudcroft, N.M., expects to have a new direct potable reuse system up and running by next summer, and projects the system will provide 40,000 of the approximately 70,000 gallons used daily by the town [4]. Brownwood, Texas, has plans to start direct potable reuse - it's just waiting for city council approval - and San Diego is considering it as an alternative to scaling its existing million-gallon-a-day indirect reuse project to 15 million gallons.

\section{CONCLUSIONS}

\section{Wave of the future}

So we have found that as public understanding of water reuse grows, so does acceptance of its practice.

Water scarcity has become an economic issue, threatening industries as well as regions and ways of life. As such, corporate leaders should begin to realize they need to get involved in finding solutions.

The need to improve efficiency in companies water use, innovate around water reuse technology and enhance water education and outreach is more evident .

Addressing water scarcity through recycling and reuse: a menu for policymakers, which highlights how policymakers should best implement water reuse and recycling based on the community needs.

Beyond wastewater being reused and recycled to help combat water shortages, it also to mention the energy in wastewater so far , the Electricity makes up 25 to 40 percent of the operating budgets for wastewater utilities and nearly 80 percent of the budgets of drinking water processing and distribution plants ${ }^{[8]}$.

With stricter regulatory and environmental constraints compounding these hurdles, our economic future may depend on how we, as entrepreneurs, manage water resources today.

The resulting water -statistics are a wake-up call: within 10 to 15 years we will not have enough available water to sustain our businesses and quality of life ${ }^{[6]}$. 
The economics of wastewater is about new revenue streams and monumental savings through water recycling.

The aging water delivery infrastructure is blamed for significant water loss and leakage. How big a challenge is this for Albanian Water?

We can do a better job at developing new techniques and technology to rehabilitate some of the infrastructure that we have in place.

\section{What is my vision for the water industry ten years from now?}

Recognizing the full lifecycle of water, valuing water closer to full cost, the Albanian society has the opportunity to make water the enabler of growth. If it doesn't, water will be the limiter of growth.

\section{References:}

[1] From drain to drink: innovations in wastewater reuse .Rachel Cernansky Ensia website

[2] Seize the economic power of wastewater .Keith Larsen June 9, 2015

[3] How to reclaim water and turn it into gold . Jonathan Lanciani November 7, 2013

[4] How Water Reuse Makes Good Sense . Heiner Merkhof November 10, 2010

[5] View from the C-Suite: American Water CEO Jeff Sterba Heather King June 13, 2011

[6] INTERNATIONAL WATER ASSOCIATION "Make cities and human settlements inclusive, safe, resilient and sustainable" - More details on https://sustainabledevelopment.un.org/sdg11 3 Refer to the Lisbon Charter 4 Refer to "IWA's

[7] IWA -Manual of the Human Rights to Safe Drinking Water and Sanitation for Practitioners". http://www.iwapublishing.com

[8] IWA Integrated water Resources Management Charter (in drafting) 7 OECD Principles on Water Governance, 2015 